Article

\title{
Control Technology of Surface Movement Scope with Directional Hydraulic Fracturing Technology in Longwall Mining: A Case Study
}

\author{
Zhanjie Feng ${ }^{1}$, Wenbing Guo ${ }^{1,2, *}$, Feiya $\mathrm{Xu}^{1}{ }^{1}$, Daming Yang ${ }^{3}$ and Weiqiang Yang ${ }^{1}$ \\ 1 School of Energy Science and Engineering, Henan Polytechnic University, Jiaozuo 454000, China \\ 2 Collaborative Innovative Center of Coal Safety Production in Henan Province, Henan Polytechnic University, \\ Jiaozuo 454000, China \\ 3 School of Mining and Geomatics, Hebei University of Engineering, Handan 056000, China \\ * Correspondence: guowb@hpu.edu.cn; Tel.: +86-0391-3987-902
}

Received: 8 August 2019; Accepted: 5 September 2019; Published: 9 September 2019

check for updates

\begin{abstract}
Mining-induced surface subsidence causes a series of environmental hazards and social problems, including farmland destruction, waterlogging and building damage in the subsidence area. To reduce mining damages, an innovative method of controlling the surface movement scope via artificial weak planes generated by hydraulic fracturing technology was proposed in this paper. Numerical models were built to analyze the influence of weak planes with different heights and dips on the overlying strata movement. The numerical simulation results showed that the weak planes structure cut off the development of the overlying strata displacement to the surface and affected the surface movement scope. When the weak planes' dips were bigger than the angle of critical deformation, with the increase of the weak planes' heights $(0-120 \mathrm{~m})$ the advance angle of influence changed from $53.61^{\circ}$ to $59.15^{\circ}$, and the advance distance of influence changed from $173.31 \mathrm{~m}$ to $140.27 \mathrm{~m}$ which decreased by $30.04 \mathrm{~m}$. In applications at Sihe coal mine in China, directional hydraulic fracturing technology was used in panel 5304 to form artificial weak planes in overlying strata. The measured surface subsidence and deformation value met the numerical simulation results and the mining-induced surface movement scope reduced. Moreover, no damage occurred to the surface buildings which were predicted to be in the affected area after extraction. This technology provided a new method to protect the surface structures from damages and had great benefits for the sustainable development of coal mines.
\end{abstract}

Keywords: underground mining; surface movement scope; numerical simulation; directional hydraulic fracturing; artificial weak planes; sustainable development

\section{Introduction}

Surface subsidence is a global problem [1-3] and mostly results from human activity such as groundwater and mineral extraction and the construction of underground facilities. This problem is particularly significant within the underground longwall mining $[4,5]$ industry due to the severe disturbance to the overlying strata during the mining process (Figure 1). 


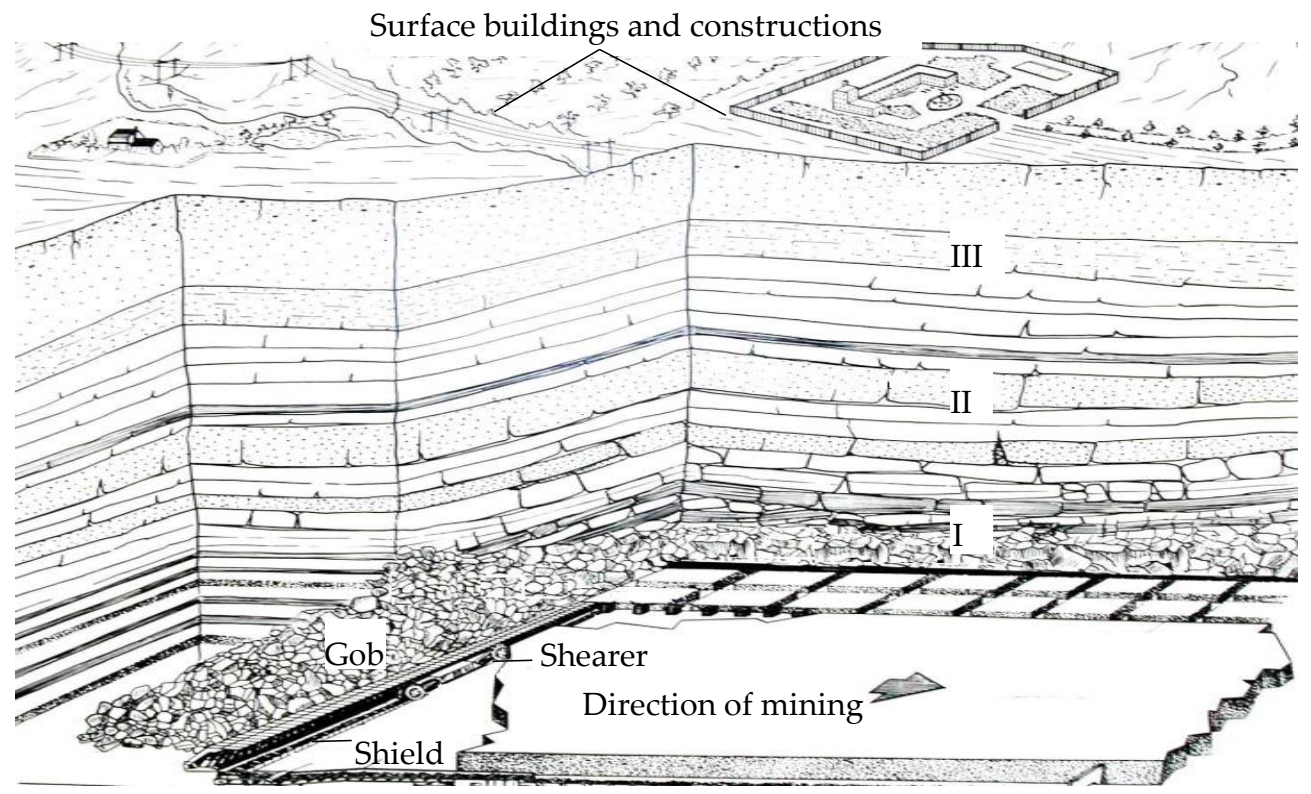

Figure 1. Cut-away view of a longwall panel showing equipment layout and overburden movement, I—caved zone; II—fractured zone; III—continuous deformation zone.

Developing effective measures to control mining-induced surface subsidence has been the focus of researchers over the past few decades.

At present, there are two main methods of mining under buildings in China.

(1) Management methods, that is, the relocation of surface buildings.

(2) Technical methods: strip mining [6,7], backfilling mining [8-10] and coordinated mining, etc.

However, these methods have their shortcomings as follows:

(1) The relocation mode has problems such as land acquisition, contradiction between workers and residents, and one-time investment in relocation funds.

(2) Strip mining [11,12] causes serious loss of resources, and its recovery efficiency is generally low, which is unfavorable to the development of the enterprise, moreover, it is difficult to ensure the long term stability of coal pillars, and the coal pillars in the gob are prone to failure and cause serious damage to the surface.

(3) For filling mining, the demand for filling materials is large, and the initial input and production costs are relatively high; the effect of reducing subsidence of grouting bed separation is poor [13], because the location of the separation layer is difficult to determine.

(4) The effect of coordinated mining [14] dealing with reducing subsidence is not good, and the resulting surface deformation position will cause seasonal water accumulation.

With the development of technology, some scholars propose the coupling of mining technology of the above. "Strip mining-gob grouting-filling-strip pillar mining" method $[15,16]$ and "mining-backfilling-keeping" method [17] combined the advantages of strip mining and backfilling mining organically.

Previously, all of the technologies above were aimed at reducing the degree of overburden deformation and subsidence to protect surface buildings and constructions. In the course of its formation and long-term geological activities, many randomly oriented strength weakening planes had formed in the rock mass, which were also called rock mass fracture surfaces or rock mass discontinuities. With the development of mining subsidence monitoring and the in-depth analysis of overlying strata movement data, Xie et al. [18] found that the development degree of mining subsidence would be completely different under the condition of the same mining factors and different geological factors. 
The surface environmental disasters in the coal mining area related to underground mining, although derived from the mining of coal seams, were essentially controlled by these rock mass discontinuities. Under different rock mass discontinuities, the extent of ground subsidence and cracking in coal mining areas caused by the same intensity of underground mining activities were significantly different. Furthermore, the surface subsidence law was significantly different from that of surface subsidence under ordinary geological conditions [19].

This paper studied the relationship between the movement characteristic of overlying strata and weak planes by means of theoretical analysis, numerical simulation and field measurement. Moreover, the technology of "mining-induced surface movement scope control by hydraulic fracturing" was put forward for the first time. The field test verified the effect of surface movement scope controlled by overlying strata hydraulic fracturing during longwall mining, providing technical support and acting as reference for similar trials investigating the mitigation of surface subsidence and building damages in coal mining districts, which is of great significance for the sustainable development of aging coal mine enterprises.

\section{Mechanism of Mining-Induced Surface Movement Scope Control by Weak Planes}

Xia et al. $[20,21]$ systematically studied the control mechanism of tectonic environment (tectonic medium, tectonic interface, tectonic stress, etc.) on coal mining subsidence from the geological point of view and put forward the theory of "tectonic control of hazards" (TCH). Tectonic weak planes are one of the important factors determining the geological environment bearing capacity of coal mining areas. Weak planes destroy the continuity of the rock strata and weaken the mechanical strength of the rock strata, controlling the deformation, failure mode and stability of the rock strata.

Taking faults as an example [22], during the advancing of the working face, the overlying rock mass above the gob is destroyed by tensile stress, which leads to the movement of rock strata since faults belong to the weak structure planes, and have no resistance to the tensile stress. When the movement of the rock strata reaches faults, the overlying strata on both sides of faults are easy to shear and slip along the fault planes. Within the influence area by underground excavation, most of the extrusion displacement and rebound deformation pointing to the gob are limited to the fault zones, which leads to different characteristics of rock strata movement and deformation on both sides of the fault planes. Guo [5] made an analysis with a profile perpendicular to the strike of the fault and studied the influence of faults on the law of strata and surface movement. When the faults dip is greater than $2^{\circ}$ and the drop of the fault is greater than $10 \mathrm{~m}$, the law of surface subsidence will get significantly different from that of surface subsidence under ordinary geological conditions. Especially, when the faults $\operatorname{dip} \alpha$ is larger than the angle of critical deformation $\delta$, the scope of surface movement above gob will reduce (Figure 2a), while the angle of critical deformation $\delta$ is larger than the faults dip $\alpha$, the scope of surface movement above gob will enlarge (Figure $2 b$ ). Therefore, the weak fault planes may aggravate the mining damage, and may slow down the mining damage.

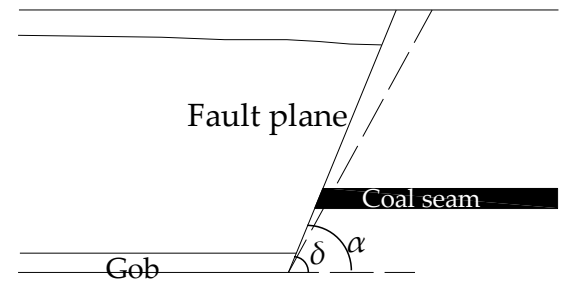

(a)

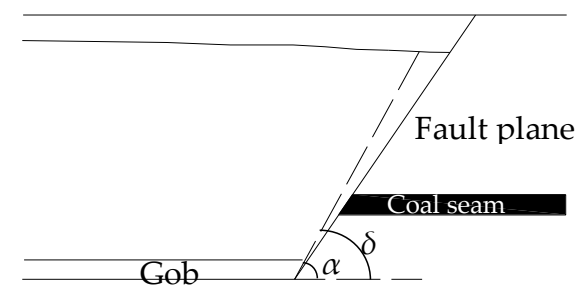

(b)

Figure 2. Fault effect towards mining subsidence. (a) The faults dip $\alpha$ is larger than the angle of critical deformation $\delta$. (b) The angle of critical deformation $\delta$ is larger than the faults $\operatorname{dip} \alpha$.

The overlying strata movement and surface subsidence caused by underground mining is a complicated process of mechanical change. Underground coal mining, roof collapse, overburden 
subsidence and surface subsidence are an overall process of excavation, stress redistribution, deformation and destruction. When solving the coal mining problem under the buildings, the angle of critical deformation $\delta$ and the loose layer deformation angle $\varphi$ are usually used to define $\mathrm{N}$ (the boundary of surface subsidence basin) from $\mathrm{M}$ (the boundary of gob) to define the mining influence scope. When the coal seam is mined out, the overlying strata can be divided into three different mining influence zones in the horizontal direction according to their vertical displacement [23]: (A) the stacking zone of broken rock block, (B) the triangular slip zone and (C) the undisturbed zone, as shown in Figure 3.

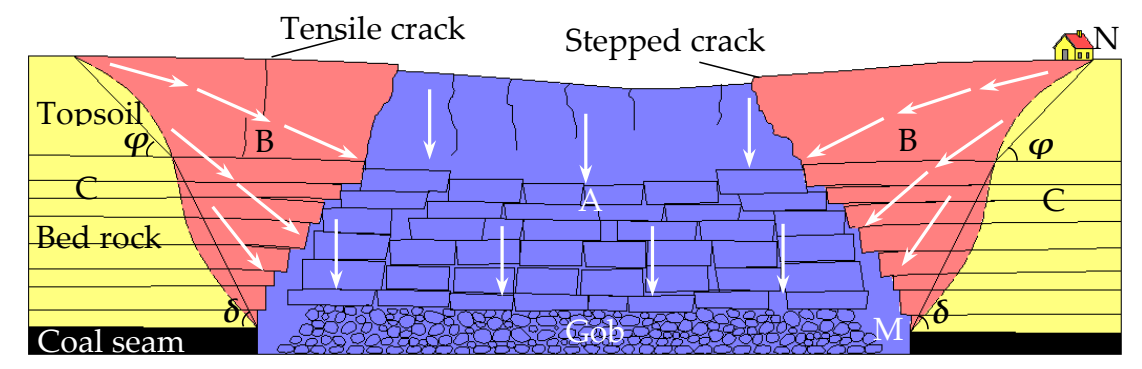

Figure 3. Horizontal zoning of overlying strata movement above the gob.

(1) The stacking zone of broken rock block.

When the underground coal seam mines out, the immediate roof of gob moves downward and bends under the action of gravity stress and overlying strata. When the internal tensile stress of the immediate roof exceeds the tensile strength of it, it breaks and collapses one after another. Then, the main roof moves and bends along the normal direction of the bedding plane in the form of "cantilever beam" structure, resulting in fracture and separation. Because of the stress redistribution in the rock mass around the mining area caused by strata movement, the layered bent strata subsides, and the collapsed and fractured rock blocks are compacted gradually.

In this area, the rock strata are severely broken, and there is a general lack of force between the broken rock blocks in the horizontal direction. When the upper rock blocks break, they simply pile up on the lower broken rock blocks and fill the gob. Therefore, this area is named as "the stacking zone of broken rock block".

(2) The triangular slip zone (also known as "laminated beam" structure zone with dislocation end).

With the advancing of the working face and the continuing development of the overburden movement, the gob gradually compacts. The bedrock strata besides the gob gradually dislocate upward from the coal seam, forming a "laminated beam" structure. Due to the uncompacted space in the gob, the "laminated beam" structure rotates and moves toward the gob, forming "the triangular slip zone" [24]. According to the morphological characteristics of laminated beams in this area, Yan [23] also vividly named the composite beam as the "laminated beam structure zone with dislocation end". The boundary between "the triangular slip zone" and "the undisturbed zone" is the mechanical boundary. The rock strata in the undisturbed zone bear primary rock stress only, while the rock strata in the "triangular slip zone" bear both primary rock stress and side abutment stress. When the mining area is large enough, the bottom-up rock movement develops to the surface gradually, and the overburden subsides in an inverted trapezoid, forming a subsidence deformation basin on the surface with a much larger size than the gob area [1].

(3) The undisturbed zone.

The rock strata in this area is not disturbed. There is no change in the stress and displacement, and surface is not disturbed in this area.

In the field of coal mining, hydraulic fracturing technology was proposed as an effective method to fracture hard rock mass, achieving strength weakening, stress release, crack expansion and slowing of mine pressure. Li et al. [25] proposed hydraulic fracturing for hard top-coal and optimization of the caving process to lower the integrity and strength of the top-coal, and upgrade its crushing effect to 
weaken the support load effectively during the weight period, which reduces the likelihood of chock support accidents occurring. Yan et al. [26] explored the mechanism of hydraulic fracturing dealing with a hard roof. Huang et al. [27] constructed the hydraulic fracturing theory and technological framework of coal and rock mass. Successful field tests in the Tongxin coal mine (Datong mine area, China) showed that hydraulic fracturing in both a hanging roof over an adjacent gob area and in the gob area behind the advancing working face controlled the behavior of strong strata material on the gob-side in longwall mining and also guaranteed safe extraction at the working face. Yu et al. [28] took Tashan coal mine (Datong mine area, China) as an example and performed ground hydraulic action experiments on the high-level hard rock strata. The experiments changed the fracturing structures of the high-level rock strata and controlled the strong strata behavior successfully, thereby relieving the stress concentration around the working face. Feng et al. [29] used the Polish-like drilling and grooving method to control the expansion of the fracture surface. In his study, the hydraulic fracturing technology was successfully applied to the top of the hard roof of the working face for the first time in Wangtaipu coal mine (Jincheng Anthracite Mining Group, China), avoiding the safety hazard caused by a large-scale roof collapse. The test results showed that the transverse notch was introduced successfully in the roof by means of KZ54 drill and was capable of reducing the pressure required for crack breakdown during the directional hydraulic fracturing. The inflatable straddle packers adopted for borehole sealing ensures the stepwise fracturing in the hard strata, the stepwise fracturing could create multiple cracks in the roof. This test proved the feasibility of hydraulic fracturing in a hard rock formation. However, no field trials of this technique had been implemented in controlling mining-induced surface subsidence scope in China, and thus, ability to control subsidence in mining influenced area has yet to be demonstrated. In this study, field trials using this technique were carried out during longwall mining under buildings in the Sihe coal mine, China.

Within the influence area by underground excavation, the existence of weak planes would change the normal distribution law of displacement field and stress field of surrounding rock strata. The broken zone formed by crisscrossed weak planes played the role of a barrier affecting the deformation and stress propagation of overlying strata, as shown in Figure 4.

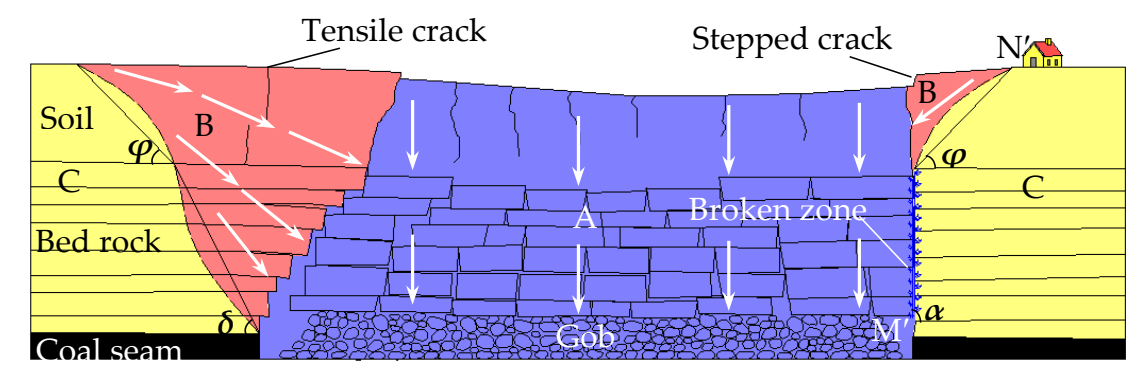

Figure 4. Horizontal zoning of overlying strata movement above the gob under the influence of weak planes.

The weak planes destroyed the cohesion of rock mass, and the rock stratum was easy to slide along the fault under the action of high-strength shear stress. Due to the barrier effect of the weak planes on the movement of the overlying strata, the boundary of the surface movement basin redrew by the broken zone dip $\alpha$ and the loose layer deformation angle $\varphi$ and moves from $\mathrm{N}$ to $\mathrm{N}^{\prime}$ (Figure 4). Obviously, the scope of the triangular slip zone decreased while the scope of the undisturbed zone expanded, achieving the purpose of controlling the surface movement scope and protecting the surface buildings.

\section{Numerical Simulation Analysis}

To verify the effectiveness of the proposed method, numerical simulations were performed to study the influence of weak planes on overlying strata movement. The discontinuity characteristics in 3DEC software could well express the faults, joints and contact surfaces encountered in mining, and 
the sliding, opening and closing of the above structural planes could be well simulated. The program could also better calculate the movement and deformation of overlying strata caused by coal seam excavation and revealed the variation law of displacement field of overlying strata.

\subsection{Description of Mining and Geological Conditions}

Sihe coal mine is located in Jincheng City, Shanxi Province, China (Figure 5). The coalfield area is $114.5 \mathrm{~km}^{2}$ with 15 coal seams, of which $3 \#$ coal seam and $5 \#$ coal seam are the main workable seams. The panel 5304 is $245.7 \mathrm{~m}$ wide and $3212.7 \mathrm{~m}$ long on average. The coal seam designed for panel 5304 belongs to the $3 \#$ coal seam with an average thickness, depth and dip angle of $6.1 \mathrm{~m}, 240 \mathrm{~m}$ and $3^{\circ}$ (nearly horizontal), respectively. The simplified stratigraphic column of the panel 5304 is shown in Figure 6.

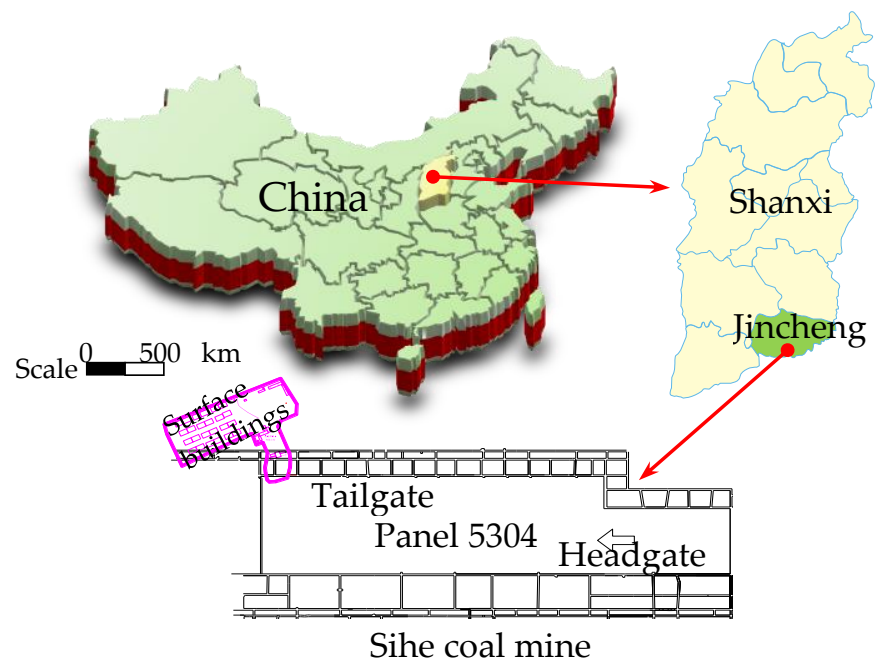

Figure 5. Location of Sihe coal mine, Jincheng City, Shanxi Province, China.

\begin{tabular}{|c|c|c|c|c|}
\hline \multicolumn{2}{|c|}{ Column } & Lithology & Thickness (m) & Depth (m) \\
\hline 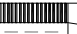 & 1 & Topsoil & 5.2 & 5.2 \\
\hline$=$ & 2 & Sandy mudstone & 9.3 & 14.5 \\
\hline$\cdots$ & 3 & Fine sandstone & 7.81 & 22.31 \\
\hline & 4 & Coarse sandstone & 5.82 & 28.13 \\
\hline & 5 & Fine sandstone & 8.1 & 36.23 \\
\hline$\because \therefore$ & 6 & Medium sandstone & 5.6 & 41.83 \\
\hline & 7 & Sandy mudstone & 9.65 & 51.48 \\
\hline & 8 & Siltstone & 7.25 & 58.73 \\
\hline & 9 & Fine sandstone & 8.5 & 67.23 \\
\hline$=$ & 10 & Medium sandstone & 5.3 & 72.53 \\
\hline & 11 & Mudstone & 9.2 & 81.73 \\
\hline & 12 & Sandy mudstone & 8.35 & 90.08 \\
\hline & 13 & Medium sandstone & 4.61 & 94.69 \\
\hline & 14 & Coarse sandstone & 6.08 & 100.77 \\
\hline & 15 & Siltstone & 6.25 & 107.02 \\
\hline & 16 & Fine sandstone & 7.5 & 114.52 \\
\hline & 17 & Sandy mudstone & 11.2 & 125.72 \\
\hline & 18 & Fine sandstone & 8.7 & 134.42 \\
\hline$-\ldots$ & 19 & Sandy mudstone & 7.55 & 141.97 \\
\hline$=$ & 20 & Fine sandstone & 8.36 & 150.33 \\
\hline$\ldots \cdots$ & 21 & Mudstone & 8.54 & 158.87 \\
\hline & 22 & Medium sandstone & 14.3 & 173.17 \\
\hline & 23 & Mudstone & 6.84 & 180.01 \\
\hline & 24 & Fine sandstone & 9.59 & 189.6 \\
\hline & 25 & Mudstone & 7.87 & 197.47 \\
\hline$. \cdots \cdots \cdot . .$. & 26 & Medium sandstone & 12.1 & 209.57 \\
\hline$\ldots$ & 27 & Fine sandstone & 8.1 & 217.67 \\
\hline $\begin{array}{l}-z- \\
-\overline{-z}\end{array}$ & 28 & Mudstone & 9.3 & 226.97 \\
\hline & 29 & Siltstone & 6.3 & 233.27 \\
\hline & 30 & Coal & 6.1 & 239.37 \\
\hline & 31 & Sandy mudstone & 10.3 & 249.67 \\
\hline
\end{tabular}

Figure 6. The stratigraphic column of the panel 5304. 


\subsection{Model Construction and Simulation Plans}

\subsubsection{Introduction of 3DEC Software}

The 3DEC 5.20 software is based on the theory of UDEC software. According to Newton's second law and stress-displacement law, it deals with the mechanical behavior of rock blocks and joints. 3DEC regards the research object as a set of two basic elements, continuity (such as rock mass) and discontinuity (such as structural plane) and defines the mechanical behavior of these basic elements by mechanical laws. Firstly, the motion of blocks is calculated by Newton's second law, and the velocity and displacement of blocks are calculated by known forces. Then, combined with the stress-displacement law, according to the displacement of blocks, the stress between discontinuous planes in rock mass is calculated as the initial boundary condition for the next time order calculation.

\subsubsection{Establishment of Model and Selection of Parameters}

(1) Determination of Model Size

In the construction of the model, there was an influence area from the excavation area to the boundary of the model, and the dip angle of the model coal seam was taken as $0^{\circ}$ according to the horizontal coal seam. The simulated size designed to be $800 \mathrm{~m} \times 250 \mathrm{~m} \times 10 \mathrm{~m}$ (length $\times$ height $\times$ width) along the incline of the working face and the roof to surface, as shown in Figure 7 . In the model, the rock strata with a width of $10 \mathrm{~m}$ and a low mechanical property was used to simulate the broken zone formed by hydraulic fracturing [30]. The 3DEC analysis software has the function of dividing joints, and the reasonable division of joints can improve the quality of simulation analysis. The principles of joint division in this paper are as follows:

1. The division of joints in the surface soil layer is smaller than that in general bedrock, and the size of its fragmentation is relatively small.

2. The fragmentation of the joints of the key layers in the bedrock is longer than that of other strata, and the division is mainly based on the fracture distance.

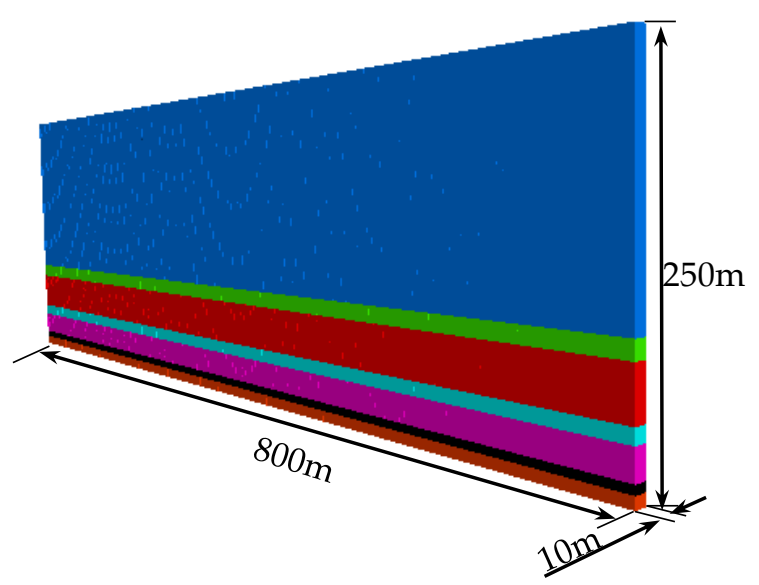

Figure 7. Mechanical model of numerical simulation.

(2) Determination of Boundary Conditions

- The horizontal displacement was fixed at the lateral boundary.

- The vertical displacement was fixed at the bottom boundary.

- The model is directly simulated to the surface, so the top is a free boundary, and the model is only affected by its own gravity. 
(3) Selection of parameters

The selection of mechanical parameters comprehensively considered the geological conditions and overburden conditions of the coal seam (Table 1). The Mohr-Coulomb failure criterion was adopted. The properties required for the model are density, bulk modulus, shear modulus, internal friction angle, cohesion and tensile strength. The mathematical relationships of these properties are as follows:

$$
\begin{aligned}
& K=\frac{E}{3(1-2 v)} \\
& G=\frac{E}{2(1+v)}
\end{aligned}
$$

where $K$ is bulk modulus, $E$ is Young's modulus, $G$ is shear modulus and $v$ is Poisson's ratio.

\begin{tabular}{|c|c|c|c|c|c|c|}
\hline Parameters & $\begin{array}{l}\text { Density } \\
\left(\mathrm{kg} \cdot \mathrm{m}^{-3}\right)\end{array}$ & $\begin{array}{l}\text { Bulk Modulus } \\
\text { (GPa) }\end{array}$ & $\begin{array}{l}\text { Shear Modulus } \\
\text { (GPa) }\end{array}$ & $\begin{array}{c}\text { Tensile } \\
\text { Strength (MPa) }\end{array}$ & $\begin{array}{l}\text { Cohesion } \\
\text { (MPa) }\end{array}$ & $\begin{array}{c}\text { Internal Friction } \\
\text { Angle }\left(^{\circ}\right)\end{array}$ \\
\hline Topsoil & 1300 & 0.41 & 0.15 & 0.8 & 0.1 & 20 \\
\hline Mudstone & 2220 & 2.8 & 1.2 & 1.3 & 1.5 & 18 \\
\hline Fine sandstone & 2650 & 1.9 & 0.95 & 1.1 & 0.78 & 25 \\
\hline Coarse sandstone & 2200 & 6.3 & 2.1 & 5.8 & 1.37 & 30 \\
\hline Medium sandstone & 2460 & 3.5 & 1.78 & 1.5 & 0.89 & 27 \\
\hline Siltstone & 2300 & 3.4 & 1.7 & 1.45 & 3.2 & 20 \\
\hline Sandy mudstone & 2100 & 2.7 & 1.2 & 1.3 & 1.5 & 18 \\
\hline 3\# coal seam & 1800 & 2.8 & 0.74 & 1.2 & 2.3 & 38 \\
\hline Broken zone & 2400 & 0.082 & 0.038 & 0.25 & 0.5 & 30 \\
\hline
\end{tabular}

Table 1. Physical and mechanic parameters of rock lithology employed in the numerical simulations.

\subsection{Numerical Simulation Results and Analysis}

Four numerical models (Plan I) with the same weak planes dip of $90^{\circ}$ but different weak planes heights $(0,60 \mathrm{~m}, 90 \mathrm{~m}$ and $120 \mathrm{~m})$ as changing conditions (a d); four numerical models (Plan II) with the same weak planes height of $60 \mathrm{~m}$ but different weak planes dips $\left(0,30^{\circ}, 60^{\circ}\right.$ and $\left.90^{\circ}\right)$ as changing conditions (e h) were established as shown in Figure 8.

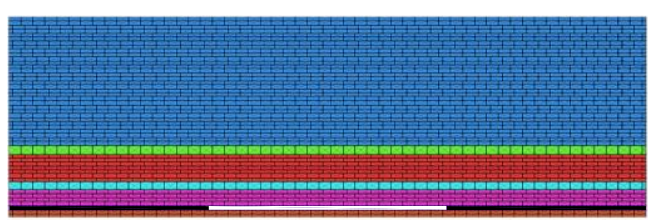

(a)

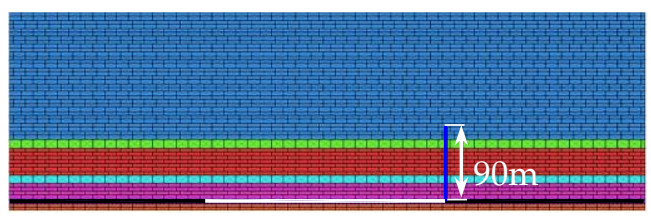

(c)

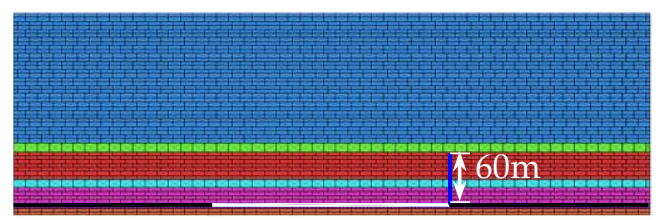

(b)

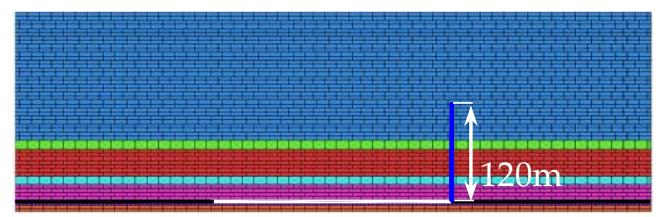

(d)

Plan I Numerical simulation models of different weak planes heights.

Figure 8. Cont. 


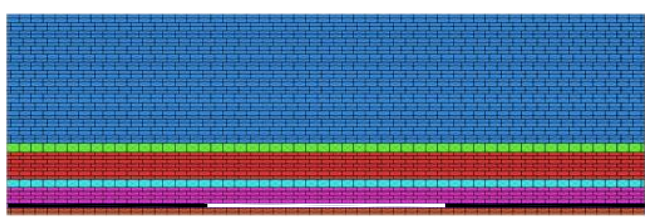

(e)

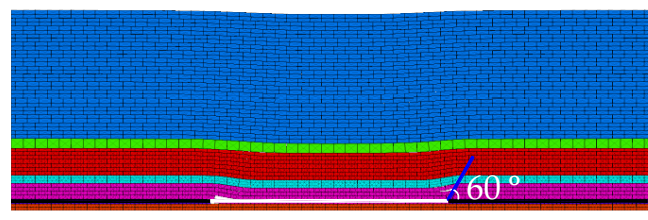

(g)

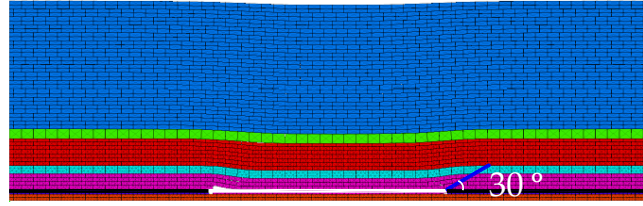

(f)

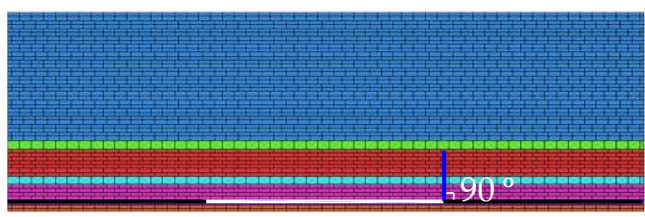

(h)

Plan II Numerical simulation models of different weak planes dips

Figure 8. Numerical simulation models.

The coal seam was excavated and the gob was stable, the displacement fields of overburden strata in the direction of inclination under different conditions were as shown in Figure 9.

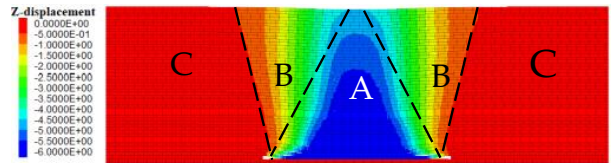

(a)

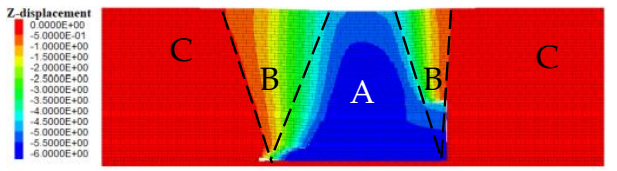

(c)
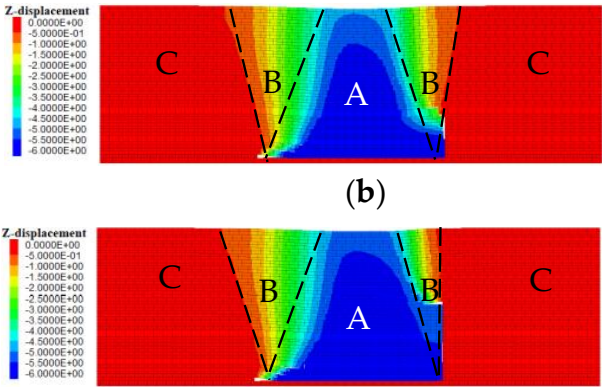

(d)

Plan I Distribution of displacement field under different weak planes heights

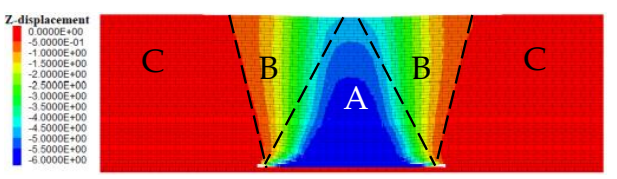

(e)

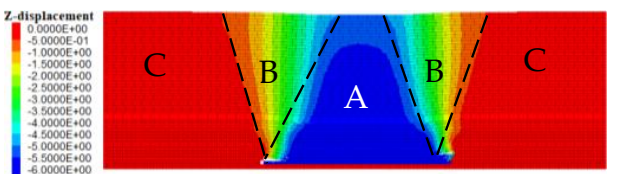

(g)
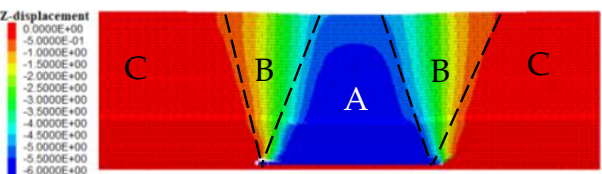

(f)
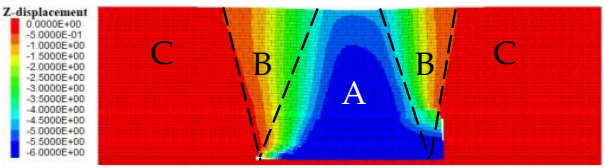

(h)

Plan II Distribution of displacement field under different weak planes dips

Figure 9. Distribution of displacement field of overburden.

The broken block in the lower key stratum at the end could not be able to articulate with the incompletely fractured rock stratum in front of it, and formed a "cantilever beam" structure together, while the high key stratum showed the articulation characteristics of the "voussoir beam" structure. According to the distribution of vertical displacement field of overburden (Figure 9), the overburden were divided into three different mining influence zones in the horizontal direction: (A) the stacking zone of broken rock block, (B) the triangular slip zone and (C) the undisturbed zone, as mentioned in Section 2. 
In the case of a normal caving working face (Figure 9a,e), due to the geometric symmetry of the excavation area itself, the distribution regularity and symmetry of the vertical displacement field of surrounding rock in the two sides of the gob were obvious after excavation. When there had been a broken zone in the mining affected area, the vertical displacement distribution of excavated surrounding rock were as shown in Figure $9 \mathrm{~b}-\mathrm{d}, \mathrm{f}-\mathrm{h}$ with weak planes heights of $60 \mathrm{~m}, 90 \mathrm{~m}, 120 \mathrm{~m}$ and weak planes dips of $30^{\circ}, 60^{\circ}$ and $90^{\circ}$, respectively. Owing to the strength of the weak planes, they were generally lower than that of the rock mass on both sides of it, therefore it was easier for the rock mass to deform and destroy at the broken zone [31]. With the change of rock mass potential energy in the mining affected area, the work done by the gravity stress was mainly consumed by the frictional action and the slip deformation of the weak planes, which made it difficult to move across the broken zone and spread farther outward. The movement and deformation of rock mass directing to gob were limited to the broken zone. Therefore, the displacement of rock mass near the broken zone was obviously large, while the displacement of surrounding rock on the other side of the broken zone was relatively small, showing the barrier effect of the broken zone on the displacement field, and the scope of the triangular slip zone (B) reduced. Under the same burial depth and mining height, the barrier effect became more obvious as the weak planes heights increased.

According to the new "Rules for the mine extraction and coal pillars establishment under buildings, water bodies, railways and main laneways" [32] promulgated and implemented on July 1, 2017, the location where the surface deformation value reaches $10 \mathrm{~mm}$, is usually considered the influencing boundary by mining. The influencing boundaries under different conditions were drawn, as shown in Figure 10.

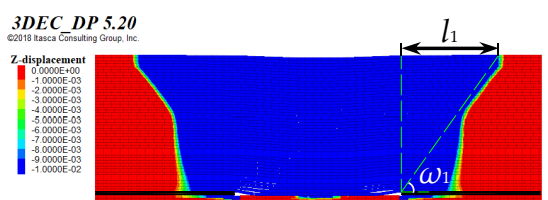

(a)

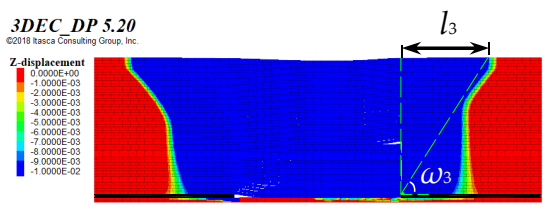

(c)

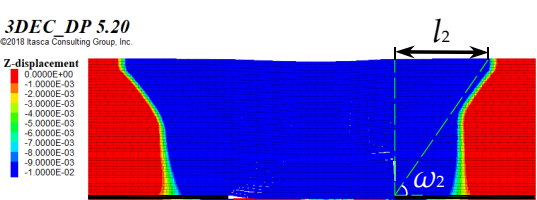

(b)

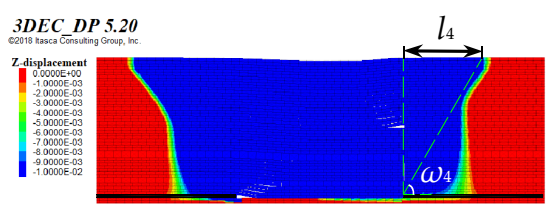

(d)

Plan I Surface movement boundary under different weak planes heights.

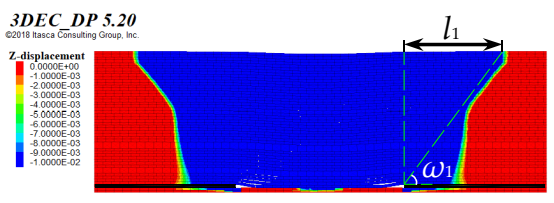

$(\mathbf{e})$

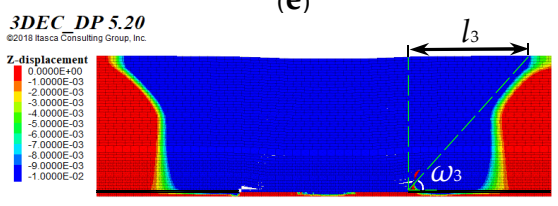

(g)

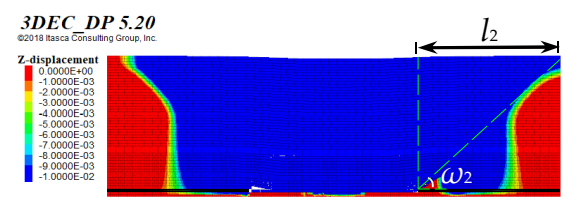

$(\mathbf{f})$

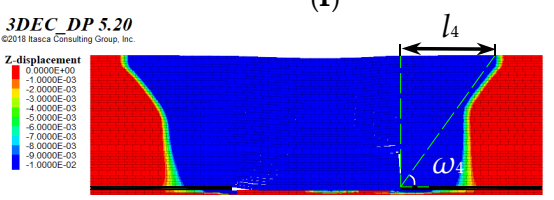

(h)

Plan II Surface movement boundary under different weak planes dips.

Figure 10. Surface movement boundary. 
In Figure 10, the angle between the connecting line (which connects the line that affects the position of the boundary point and the working face on the side of the coal pillar) and the horizontal line is called the advance angle of influence, which is expressed in $\omega$. The horizontal distance from the influencing boundary point to the working face is called advance distance of influence, which is expressed in $l$. Finally the numerical simulation results under different fault heights (Table 2) and different fault dips (Table 3) were obtained.

Table 2. Numerical simulation results of influence of weak planes heights on surface movement.

\begin{tabular}{ccccc}
\hline Plan & Model & $\begin{array}{c}\text { Weak Planes } \\
\text { Heights }(\mathbf{m})\end{array}$ & $\begin{array}{c}\text { Advance Angle of } \\
\text { Influence }\left({ }^{\circ}\right)\end{array}$ & $\begin{array}{c}\text { Advance Distance } \\
\text { of Influence (m) }\end{array}$ \\
\hline \multirow{3}{*}{$\mathrm{I}$} & $\mathrm{a}$ & 0 & 53.61 & 173.31 \\
& $\mathrm{~b}$ & 60 & 54.57 & 167.13 \\
& $\mathrm{c}$ & 90 & 56.59 & 154.81 \\
$\mathrm{~d}$ & 120 & 59.15 & 140.27 \\
\hline
\end{tabular}

Table 3. Numerical simulation results of influence of weak planes heights on surface movement.

\begin{tabular}{ccccc}
\hline Plan & Model & $\begin{array}{c}\text { Weak Planes Dips } \\
\mathbf{(}^{\circ}\end{array}$ & $\begin{array}{c}\text { Advance Angle of } \\
\text { Influence }\left({ }^{\circ}\right)\end{array}$ & $\begin{array}{c}\text { Advance Distance } \\
\text { of Influence (m) }\end{array}$ \\
\hline \multirow{3}{*}{ II } & e & 0 & 53.61 & 173.31 \\
& f & 30 & $<45$ & $>250$ \\
& g & 60 & 48.26 & 209.83 \\
h & 90 & 54.57 & 167.13 \\
\hline
\end{tabular}

The tables above show that the movement boundary of the rock layer had the following rules due to the influence of weak planes.

(1) After the coal seam excavation was completed and the model was stable, the advance angle of influence changed from $53.61^{\circ}$ to $59.15^{\circ}$ with weak planes heights ranging from $0 \mathrm{~m}$ to $120 \mathrm{~m}$, and the advance distance of influence changing from $173.31 \mathrm{~m}$ to $140.27 \mathrm{~m}$ which decreased by $30.04 \mathrm{~m}$.

(2) Compared with the condition without weak planes, when the weak planes dips were $30^{\circ}$ and $60^{\circ}$, the advance distance of influence increased to more than $250 \mathrm{~m}$ and $209.83 \mathrm{~m}$, respectively. Meanwhile, the advance angle of influence decreased to less than $45^{\circ}$ and $48.26^{\circ}$, respectively. However, when the weak planes dip was $90^{\circ}$, the advance distance of influence decreased to $167.13 \mathrm{~m}$, and the advance angle of influence increased to $54.57^{\circ}$.

To show the influence of different types of weak planes on surface subsidence characteristics vividly, the comparison diagram of surface subsidence curves was drawn based on the simulation results, as shown in Figure 11.

The surface subsidence curves of Plan I and Plan II were compared in Figure 11. When there were no weak planes, the surface subsidence curve (the black line) symmetrically distributed after mining, and the maximum subsidence point $(4537.88 \mathrm{~mm})$ of the surface appeared in the middle of the working face. When there were weak planes with height of $120 \mathrm{~m}$ and dip of $90^{\circ}$ at the end of the working face, the maximum subsidence curve (the magenta line) became asymmetric obviously, and the maximum value reached $5204.33 \mathrm{~mm}$. The boundary point of the surface subsidence basin both shifted to the broken zone, and the surface mining influence scope decreased. With the increase of weak planes height, the mining influence scope showed a decreased trend. In Plan II, compared with the angle of critical deformation $\left(57^{\circ}\right)$ in Sihe coal mine, when there were weak planes of which dips were smaller than the angle of critical deformation in overburden, the surface mining influence scope increased obviously. When there were weak planes which dips were far greater than the angle of critical deformation in overburden, the surface mining influence scope would decrease. 


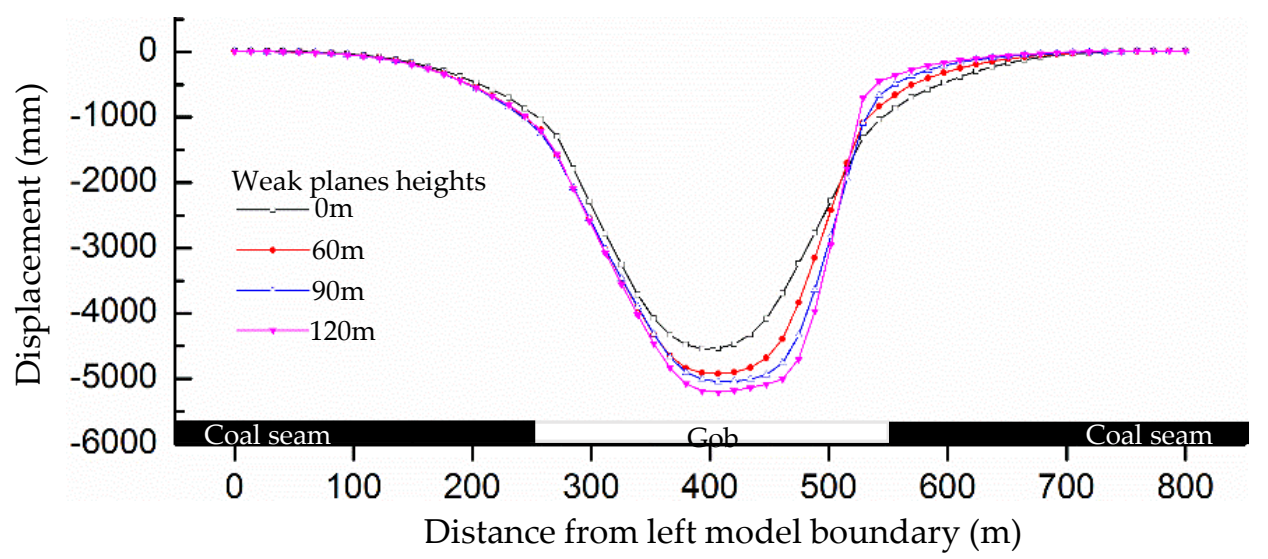

Plan I Surface subsidence curves under different weak planes heights

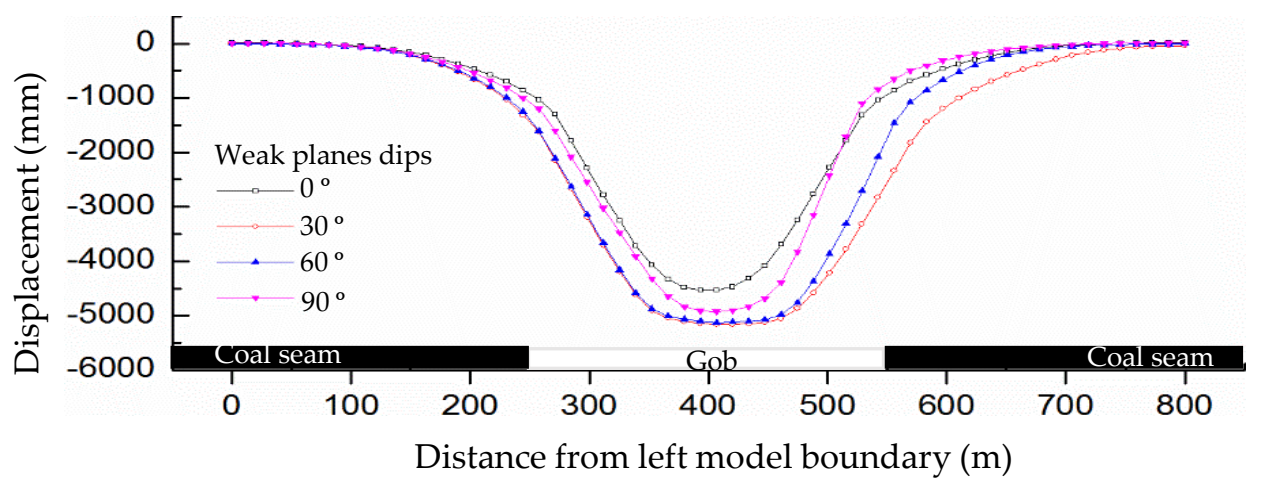

Plan II Surface subsidence curves under different weak planes dips

Figure 11. Surface subsidence curves under different types of weak planes.

In the numerical models established in this paper, the broken zone created by directional hydraulic fracturing was regarded as homogeneous weakened rock strata, and the actual fracturing zone was composed of a complex fracture network. Future research work will be conducted to establish a numerical model considering the complex fracture network formed in overburden, and further study the effects of weak planes on mining-induced overlying strata deformation and surface movement.

\section{Case Studies}

\subsection{Study Area Overview}

There are extensive buildings nearby besides the main remove gateway of panel 5304, as shown in Figure 12.

Mining subsidence prediction was used to assess possible subsidence influences on surface structures based on the probability-integral method. According to the specific geological conditions of panel 5304, the calculated parameters were as follows: subsidence factor $q=0.83$; displacement factor $b$ $=0.21$; tangent of major influence angle $\tan \beta=2.4$; influence transference angle $\theta=86.6^{\circ}$. Taking these parameters into account, the predicted results were visualized by Surfer software, and the surface subsidence contour map of the 5304 working face after mining was fitted, as shown in Figure 13. 


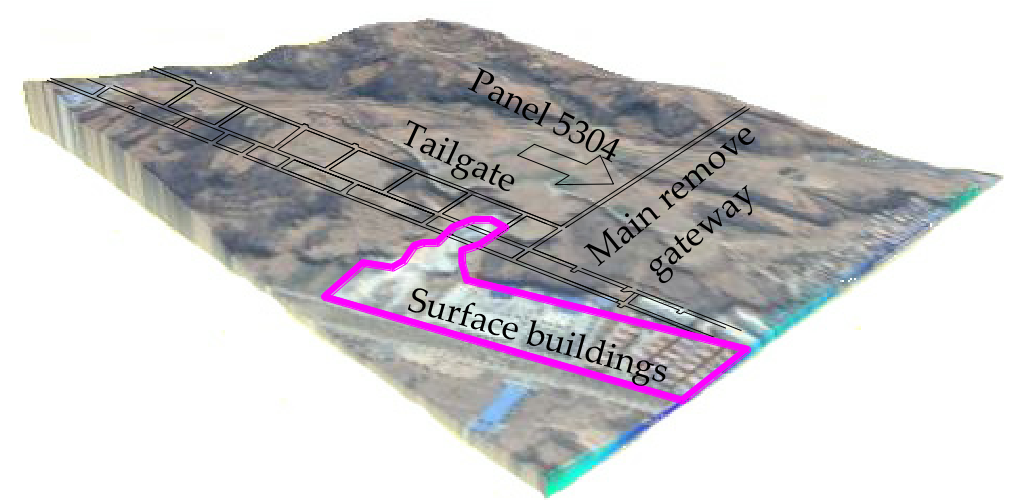

Figure 12. Surface buildings besides the panel 5304.

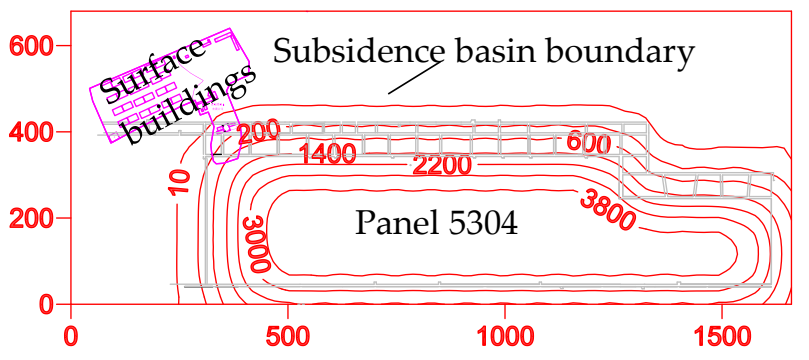

Figure 13. Surface subsidence contour line.

Taking the subsidence of $10 \mathrm{~mm}$ as the surface moving basin boundary, the calculated contour lines of surface subsidence and the most external influence boundary (the surface subsidence $10 \mathrm{~mm}$ contour line) are shown by the red line in Figure 13. It was obvious that some surface buildings (structures) were in the mining influence scope of panel 5304.

To control the mining damage effectively, overburden hydraulic fracturing technology was applied to create artificial weak planes in the tailgate of panel 5304 according to the spatial position relationship between surface buildings and working face, as shown in Figure 14.

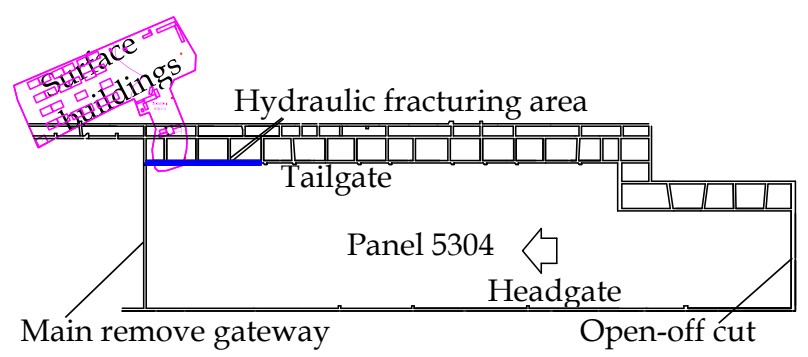

Figure 14. Hydraulic fracturing testing area.

\subsection{Design of Overburden Hydraulic Fracturing}

Hydraulic fracturing weakening should be coordinated with mining work in time and space. The hydraulic fracturing at the face end generally was carried out before mining, and artificial hydraulic cracks generated in the target rock layer in advance to weaken the overburden, based on the bearing pressure distribution and the hydraulic fracturing weakening characteristics, the hydraulic fracturing construction site is determined. At the same time, considering the safety of underground hydraulic fracturing, measures should be taken to strengthen support in fracturing area to avoid water fracturing destroying the stability of roof support body, thus causing roof fall and other accidents. During field 
implementation, the effect of hydraulic fracturing on subsidence scope controlling of surface mining could be judged by the distribution of surface cracks and the observed surface subsidence value.

According to the wetting radius $R$ of the water injection hole [33], the spacing is based on the design criteria of forming through cracks. To achieve a good crushing effect, the adjacent fractured area should coincide. The maximum distance $d$ between hydraulic fracturing boreholes is twice that of the wetting radius of the water hole:

$$
d=2 R=2 \sqrt{\frac{V t g}{\pi \ln \gamma k}}
$$

where $d$ is the hydraulic-fracture drilling spacing, $R$ is the water injection hole wetting radius, $t$ is water injection time, $V$ is the water injection speed, $\gamma$ is the rock bulk density, $\mathrm{n}$ is the fractional rock water absorption, $k$ is the nonuniform coefficient $(0.08-0.2), l$ is the length of the water injection hole.

According to the numerical simulation results and site's operational conditions, the borehole positions were chosen to be $1 \mathrm{~m}$ from the coal wall. The borehole length was $60 \mathrm{~m}$, the angle between the borehole and the axis of the tunnel was $5^{\circ}$, the angle of elevation was $70^{\circ}$, and the borehole spacing was $10 \mathrm{~m}$. During the hydraulic fracturing, we adopted the backward fracturing method and used a KZ54 type cutting drill bit to prefabricate multiple radial cutting grooves in the rock layer to increase the number of fractures at the surface. A 3ZSB80/62-90 type high pressure water pump was used in the same drill to form a hydraulic-fracture zone from the bottom of the hole to the bottom every $1.5 \mathrm{~m}-2 \mathrm{~m}$. A technical diagram of the hydraulic fracturing progress is shown in Figure 15.

(1) Before mining, drill holes were arranged according to the set drilling parameters on the roof of the tailgate. When the bit drilled to the slotting position, the slotting bit replaced and grooved at the bottom of the borehole. After grooving, the slotting bit withdrew, and the ordinary bit replaced it to continue drilling. Then the grooving process was carried out at the next slotting position, so that the drilling cycle would be completed at the end of the drilling, as shown in Figure 15c.

(2) Then, the inflatable straddle packer used to seal the fracturing section before and after grooving, and the backward fracturing method used for sealing and water injection fracturing, that is, from the groove at the bottom of the borehole to the outward sequential fracturing. The high-pressure water pump was connected with water first and then electrified, and then slowly pressurized. At the same time, the pressure gauge data of the pump and manual pump recorded. The pressure would continue to pressurize until the pre-crack cracks occurred. At this time, the pressure would suddenly drop, and the pressure-retaining water injection would make the cracks continue to expand. When water seeped out from the roof, coal wall or borehole of the roadway, the fracturing stopped immediately, and the main hydraulic crack and branch airfoil crack was created in the overburden rock at the fracturing site, as shown in Figure 15b.

(3) The above operations were repeated in turn until a hydraulic fracturing broken zone intersecting airfoil branching cracks formed between boreholes as shown in Figure 15a. When the face mined near the hydraulic fracturing section, the overburden at face end slid along the broken zone under the action of overburden stratum pressure and self-gravity. 


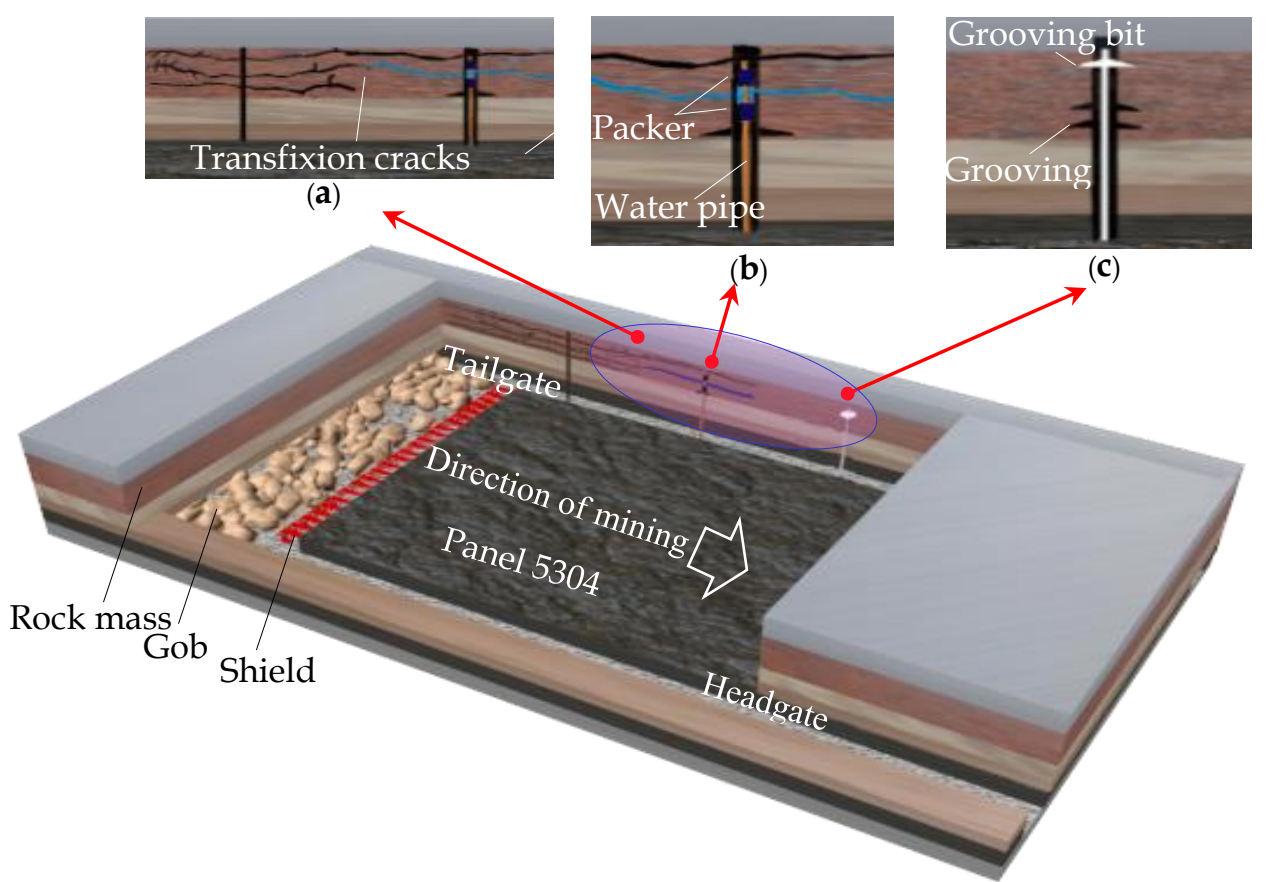

Figure 15. Hydraulic fracturing technology. (a) Cracks transfixion, (b) sealing and fracturing and (c) grooving.

\subsection{Application Effects and Field Measurements}

A subsidence observation station was established over the working surface to analyze the effect of mining on the nearby buildings after hydraulic fracturing. The setting of the displacement observation station and the layout of the working face are shown in Figure 16.

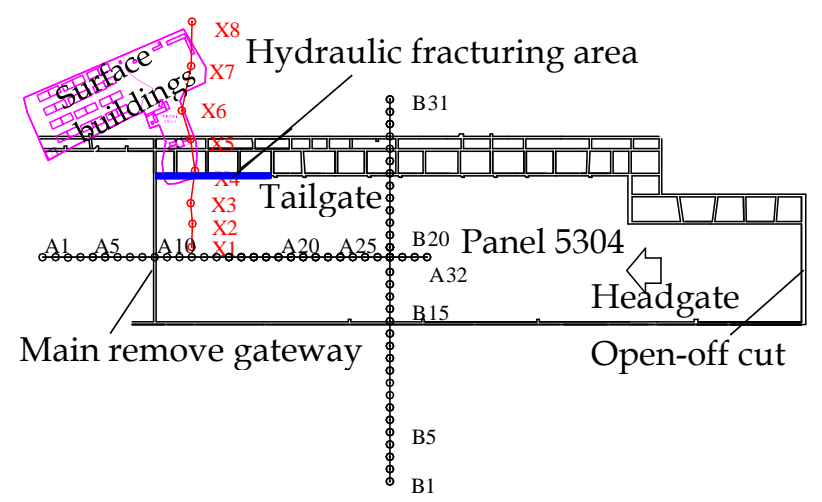

Figure 16. Layout of surface displacement observation station.

Line $\mathrm{X}$ was laid at the hydraulic fracturing area, as shown in Figure 17. In order to analyze and compare any surface movement before and after hydraulic fracturing, Origin Pro.8.6 software was used to draw the measured and the predicted maximum subsidence curve of line $\mathrm{X}$, as shown in Figure 17.

According to Figure 17, the results showed that the line $X$ subsidence curve got steeper after hydraulic fracturing, and the measured maximum subsidence value was greater than the predicted value. The mean values of the predicted and the measured subsidence were $-857.99 \mathrm{~mm}$ and -962.75 $\mathrm{mm}$, and the standard deviation of them were 1098.29 and 1262.03, respectively. The boundary point of subsidence basin moved $31 \mathrm{~m}$ to the middle of the gob after hydraulic fracturing and the mining subsidence scope reduced. 


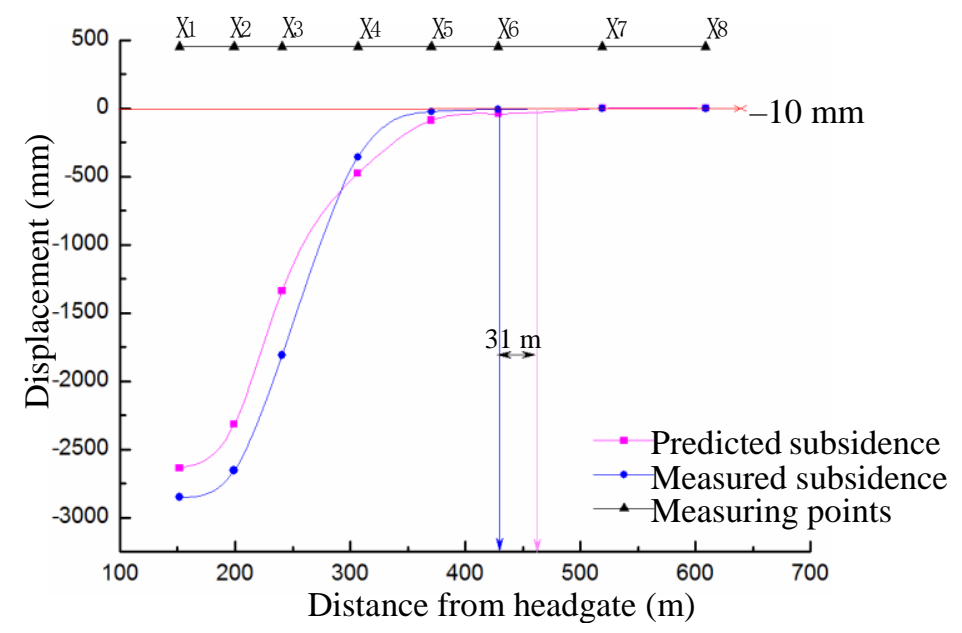

Figure 17. Comparison of predicted and measured values of line $X$.

During the field surface investigation after the end of mining of panel 5304, it was found that the collapse cracks (step drop 0.3-0.7 m) shown in Figure 18 appeared near the corresponding surface position of hydraulic fracturing section along the tailgate.

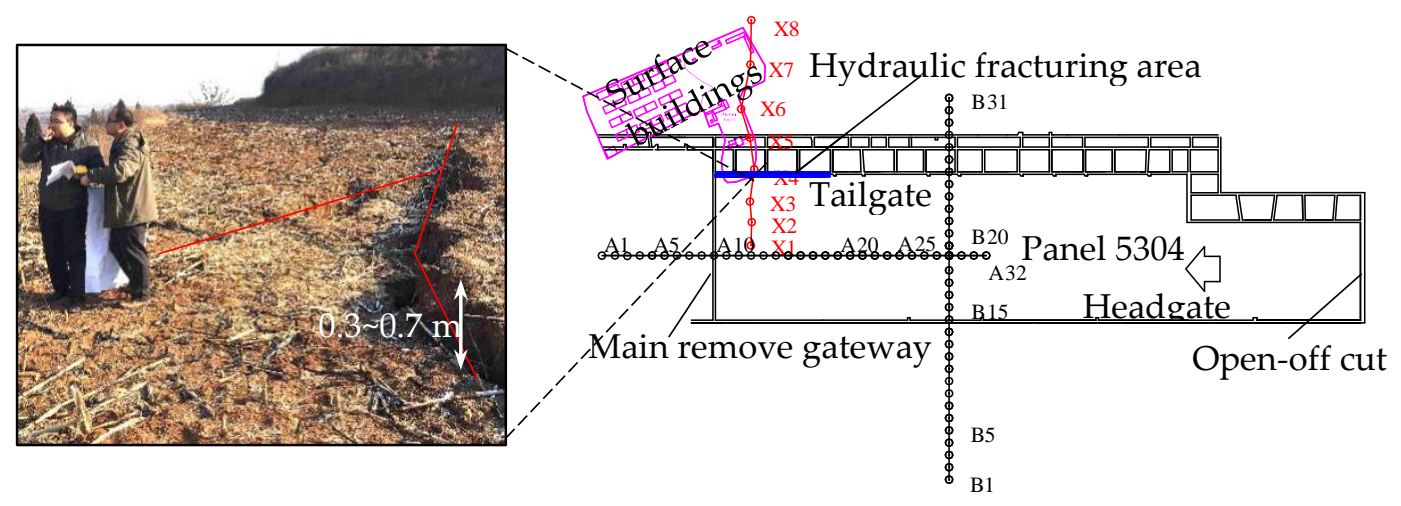

Figure 18. Surface stepped cracks at hydraulic fracturing area after mining.

However, combined with household investigation, no cracks or damage occurred after mining with hydraulic fracturing on overburden, which verified that hydraulic fracturing in overburden reduced the mining subsidence scope and protected the constructions above the surface. Moreover, control measures were proposed such as strengthening the observation of cracks evolution and cracks landfill compaction.

\section{Conclusions}

(1) After the coal seam mined out, the overburden bedrock was divided into three different mining influence zones in the horizontal direction according to vertical displacement of overburden: the undisturbed zone, the triangular slip zone and the stacking zone of broken rock block. Among them, the characteristics of the triangular slip zone was the key to controlling the surface movement scope.

(2) Numerical simulation models were established to study the influence of weak planes on overlying strata movement. When the weak planes dip was bigger than the angle of critical deformation, the advance angle of influence changed from $53.61^{\circ}$ to $59.15^{\circ}$ with weak plane heights ranging from $0 \mathrm{~m}$ to $120 \mathrm{~m}$, and the advance distance of influence changed from $173.31 \mathrm{~m}$ to $140.27 \mathrm{~m}$ which decreased by $30.04 \mathrm{~m}$. With the increase of the weak planes' height, the mining influence scope showed a decreasing trend. 
(3) The field test results of panel 5304 in Sihe coal mine showed that buildings (structures) formerly in mining-affected areas did not appear to have cracks or mining damages after mining by using hydraulic fracturing technology in overburden, which proved the feasibility of this technology. This work is of important theoretical value and practical significance to surface subsidence control and sustainable coal mining with similar geological mining conditions, and provides a new method for mining damage and protection under buildings (constructions), railways, and water bodies.

Author Contributions: W.G. conceived this paper and made modifications several times; Z.F., D.Y. and F.X. analyzed the data and calculated the results; W.Y. conducted the numerical simulation; Z.F. wrote the paper.

Funding: The authors gratefully acknowledge the financial support for this work provided by the National Natural Science Foundation of China (grant no. 51774111).

Acknowledgments: The authors wish to thank the National Natural Science Foundation of China (project No.51774111) for the financial support of this study and all the original data provided by Jincheng Anthracite Mining Group.

Conflicts of Interest: The authors declare no conflict of interest.

\section{References}

1. Peng, S.S. Topical areas of research needs in ground control-A state of the art review on coal mine ground control. Int. J. Min. Sci. Technol. 2015, 25, 1-6. [CrossRef]

2. Bell, F.G.; Donnelly, L.J. Mining and Its Impact on the Environment; CRC Press: Boca Raton, FL, USA, 2006.

3. Yilmaz, I.; Marschalko, M. A leaning historical monument formed by underground mining effect: An example from Czech Republic. Eng. Geol. 2012, 133-134, 43-48. [CrossRef]

4. Sampurna, A.; Joseph, S.; Thomas, N. Development of a flooded-bed scrubber for removing coal dust at a longwall mining section. Saf. Sci. 2018, 110, 204-213.

5. Guo, W.B. Coal Mining Damages and Protection; Coal Industry Press: Beijing, China, 2013; pp. 39-41.

6. Chen, S.J;; Wang, H.L.; Wang, H.Y.; Guo, W.J.; Li, X.S. Strip Coal pillar design based on estimated surface subsidence in eastern China. Rock Mech. Rock Eng. 2016, 49, 3829-3838.

7. Cao, W.H.; Wang, X.F.; Li, P.; Zhang, D.S.; Sun, C.D.; Qin, D.D. Wide strip backfill mining for surface subsidence control and its application in critical mining conditions of a coal mine. Sustainability 2018, 10, 700. [CrossRef]

8. Zhang, Q.; Zhang, J.X.; Wu, Z.Y.; Chen, Y. Overview of solid backfilling technology based on coal-waste underground separation in China. Sustainability 2019, 11, 2118. [CrossRef]

9. Sun, W.; Wang, H.J.; Hou, K.P. Control of waste rock-tailings paste backfill for active mining subsidence areas. J. Clean. Prod. 2018, 171, 567-579. [CrossRef]

10. Li, M.; Zhang, J.X.; An, B.F.; Deon, M.G.; Xu, Q.Q. Effect of cyclic lateral loading on the compaction behavior of waste rock backfill materials in coal mines. Energies 2019, 12, 17. [CrossRef]

11. Yu, Y.; Deng, K.Z.; Luo, Y.; Chen, S.E.; Zhuang, H.F. An improved method for long-term stability evaluation of strip mining and pillar design. Int. J. Rock Mech. Min. Sci. 2018, 107, 25-30. [CrossRef]

12. Tan, Y.; Guo, W.B.; Bai, E.H.; Yang, D.M.; Xu, G.S.; Yan, H. Overburden failure induced by instability of coal pillar in strip wongawilli mining. J. China Coal Soc. 2017, 42, 1656-1662.

13. Teng, H.; Xu J.L.; Xuan, D.Y.; Wang, B.L. Surface subsidence characteristics of grout injection into overburden: Case study of Yuandian No.2 coalmine. Environ. Earth Sci. 2016, 75, 530. [CrossRef]

14. Yu, X.Y.; Mao, X.W.; Guo, W.B. Coordinated waterproof mining mode under thick loose sand stratum in Barapukuria coal mine. J. China Coal Soc. 2019, 44, 739-746.

15. Guo, G.L.; Wang, Y.H. A new method for ground subsd application of subsidence control technology of mining coordinately mixedidence control in coal mining. J. China Univ. Min. Technol. 2004, 33, 150-153.

16. Zhu, X.J.; Guo, G.L.; Liu, H.; Yang, X.Y. Surface subsidence prediction method of backfill-strip mining in coal mining. Bull. Eng. Geol. Environ. 2019, 1-14. [CrossRef]

17. Dai, H.Y.; Guo, J.Y.; Yan, Y.G.; Li, P.X.; Liu, Y.S. Principle and application of subsidence control technology of mining coordinately mixed with backfilling and keeping. J. China Coal Soc. 2014, 39, 1602-1610. 
18. Xie, H.P.; Zhou, L.W. Application of Flac to predict ground surface displacements due to coal extraction and its comparative analysis. China J. Rock Mech. Eng. 1998, 18, 397-401.

19. Swift, G. Relationship between joint movement and mining subsidence. Bull. Eng. Geol. Environ. 2014, 73, 163-176. [CrossRef]

20. Xia, Y.C. Study of Control Mechanism of Tectonic Settings on Environment Hazards Related to Coal-Mining. Ph.D. Thesis, Xi'an University of Science and Technology, Xi'an, China, 2003.

21. Xia, Y.C.; Sun, X.Y.; Hui, D.X. The theory of tectonism controlling hazards and constructing of green mining areas. J. Xi'an Uni. Sci. Technol. 2008, 2, 331-335.

22. Bruneau, G.; Tyler, D.B.; Hadjigeorgiou, J.; Potvin, Y. Influence of faulting on a mine shaft-A case study; part I-Background and instrumentation. Int. J. Rock Mech. Min. Sci. 2003, 40, 95-111. [CrossRef]

23. Yan, W.T. Strata Movement Model Based on Laminated Beam Structure with Dislocation End under the Mining of Shallow Buried Thick Coal Seam. Ph.D. Thesis, China University of Mining and Technology, Beijing, China, 2018.

24. Wang, Y.B. Evolution mechanism of end structure and abutment pressure on fully-mechanized top coal caving face in extra thick coal seam. J. China Coal Soc. 2017, 42 (Suppl. 1), 30-35.

25. Li, Z.; Xu, J.L.; Yu, S.C.; Ju, J.F.; Xu, J.M. Mechanism and prevention of a chock support failure in the longwall top-coal caving faces: A case study in Datong coalfield, China. Energies 2018, 11, 288. [CrossRef]

26. Yan, S.H.; Ning, Y.; Kang, L.J. The mechanism of hydro breakage to control hard roof and its test study. J. Chin. Coal Soc. 2000, 25, 32-35.

27. Huang, B.X.; Liu, J.W.; Zhang, Q. The reasonable breaking location of overhanging hard roof for directional hydraulic fracturing to control strong strata behaviors of gob-side entry. Int. J. Rock Mech. Min. Sci. 2018, 103, 1-11. [CrossRef]

28. Yu, B.; Duan, H.F. Study of roof control by hydraulic fracturing in full-mechanized caving mining with high strength in extra-thick coal layer. Chin. J. Rock Mech. Eng. 2014, 33, 778-785.

29. Feng, Y.J.; Kang, H.P. Test on hard and stable roof control by means of directional hydraulic fracturing in coal mine. Chin. J. Rock Mech. Eng. 2012, 31, 1148-1155.

30. Zhou, Y.; Lin, G.; Gong, F.X.; Liu, S.L. Numerical simulations of structural deformation and fluid flow in Xiangshan deposit. J. China Univ. Min. Technol. 2006, 16, 404-408. [CrossRef]

31. Wang, X.Y.; Bai, J.B.; Wang, M. Study on asymmetric instability mechanism and control technology for roadway in deep inclined rock strata with weak plane. J. Min. Saf. Eng. 2015, 32, 544-551.

32. China National Bureau of Coal Industry. Rules for the Mine Extraction and Coal Pillars Establishment under Buildings, Water Bodies, Railways and Main Laneways; China Coal Industry Press: Beijing, China, 2017.

33. Li, J.S. Study of determination method on water infusion parameters of water pre-infusion treating top coal in fully mechanized sub-level caving mining. Coal Eng. 2004, 1, 59-63. 